\title{
The tundra phenology database: more than two decades of tundra phenology responses to climate change $^{1}$
}

Janet S. Prevéy, Sarah Claire Elmendorf, Anne Bjorkman, Juha M. Alatalo, Isabel Ashton, Jakob J. Assmann, Robert G. Björk, Mats P. Björkman, Nicoletta Cannone, Michele Carbognani, Chelsea Chisholm, Karin Clark, Courtney G. Collins, Elisabeth J. Cooper, Bo Elberling, Esther R. Frei, Gregory R.H. Henry, Robert D. Hollister, Toke Thomas Høye, Ingibjörg Svala Jónsdóttir, Jeffrey T. Kerby, Kari Klanderud, Christopher Kopp, Esther Levesque, Marguerite Mauritz, Ulf Molau, Isla H. MyersSmith, Susan M. Natali, Steven F. Oberbauer, Zoe Panchen, Alessandro Petraglia, Eric Post, Christian Rixen, Heidi Rodenhizer, Sabine B. Rumpf, Niels Martin Schmidt, Ted Schuur, Philipp Semenchuk, Jane Griffin Smith, Katharine Suding, Ørjan Totland, Tiffany Troxler, Henrik Wahren, Jeffrey M. Welker, Sonja Wipf, and Yue Yang

Received 29 October 2020. Accepted 4 May 2021.

J.S. Prevéy. U.S. Geological Survey, 2150 Centre Avenue, Building C, Fort Collins, CO 80526, USA.

S.C. Elmendorf, C.G. Collins, J.G. Smith, and K. Suding. Institute of Arctic and Alpine Research, University of Colorado, Boulder, CO 80309-0450, USA.

A. Bjorkman.* Department of Biological and Environmental Sciences, University of Gothenburg, SE-405 30 Gothenburg, Sweden; Gothenburg Global Biodiversity Centre, SE-405 30 Gothenburg, Sweden.

J.M. Alatalo. Environmental Science Center, Qatar University, Doha, Qatar.

I. Ashton. National Park Service, 820 Columbus Street, Rapid City, SD 57701, USA.

J.J. Assmann. Department of Biology, Aarhus University, DK-8000 Aarhus C, Denmark.

R.G. Björk* and M.P. Björkman.* Gothenburg Global Biodiversity Centre, SE-405 30 Gothenburg, Sweden; Department of Earth Sciences, University of Gothenburg, PO Box 460, SE-405 30 Gothenburg, Sweden.

N. Cannone. Department of Science and High Technology, Università degli Studi dell'Insubria, 2210 Como, Italy.

M. Carbognani and A. Petraglia.* Department of Chemistry, Life Sciences and Environmental Sustainability, University of Parma, Parco Area delle Scienze 11/A, I-43124 Parma, Italy.

C. Chisholm. Institute of Integrative Biology, ETH Zurich, Universitätstrasse 16, Zurich 8092, Switzerland.

K. Clark. PO Box 1320, Yellowknife, NT X1A 2L9, Canada.

E.J. Cooper. Department of Arctic and Marine Biology, Faculty of Biosciences, Fisheries and Economics, UiT-The Arctic University of Norway, N-9037 Tromsø, Norway.

B. Elberling. Center for Permafrost (CENPERM), Department of Geosciences and Natural Resource Management, University of Copenhagen, Øster Voldgade 10,1350 Copenhagen K, Denmark.

Corresponding author: Janet S. Prevéy (e-mail: jprevey@usgs.gov).

${ }^{1}$ This paper is part of a Special Issue entitled: Impacts of climate change on tundra ecosystems: Three decades of results from the International Tundra Experiment (ITEX).

*Anne Bjorkman, Robert Björk, Mats P. Björkman, Robert D. Hollister, Kari Klanderud, Zoe Panchen, Alessandro Petraglia, and Christian Rixen served as Guest Editors, Gregory R.H. Henry served as a Consulting Editor/Guest Editor, and Ingibjörg S. Jónsdóttir served as an Associate Editor/Guest Editor at the time of manuscript review and acceptance; peer review and editorial decisions regarding this manuscript were handled by Melissa Lafrenière.

() 2021 The Author(s). This work is licensed under a Creative Attribution 4.0 International License (CC BY 4.0) http:// creativecommons.org/licenses/by/4.0/deed.en_GB, which permits unrestricted use, distribution, and reproduction in any medium, provided the original author(s) and source are credited. 


\begin{abstract}
Observations of changes in phenology have provided some of the strongest signals of the effects of climate change on terrestrial ecosystems. The International Tundra Experiment (ITEX), initiated in the early 1990s, established a common protocol to measure plant phenology in tundra study areas across the globe. Today, this valuable collection of phenology measurements depicts the responses of plants at the colder extremes of our planet to experimental and ambient changes in temperature over the past decades. The database contains 150434 phenology observations of 278 plant species taken at 28 study areas for periods of 1-26 years. Here we describe the full data set to increase the visibility and use of these data in global analyses and to invite phenology data contributions from underrepresented tundra locations. Portions of this tundra phenology database have been used in three recent syntheses, some data sets are expanded, others are from entirely new study areas, and the entirety of these data are now available at the Polar Data Catalogue (https://doi.org/10.21963/13215).
\end{abstract}

Key words: Arctic, alpine, climate change, experimental warming, International Tundra Experiment (ITEX), flowering, plant, vegetation change.

Résumé : Les observations des changements dans la phénologie ont fourni certains des signaux les plus forts des effets du changement climatique sur les écosystèmes terrestres. L'expérience internationale sur la toundra ITEX (International Tundra Experiment), lancée au début des années 1990, a établi un protocole commun pour mesurer la phénologie des plantes dans les zones d'étude de la toundra à travers le monde. Aujourd'hui, cette précieuse collection de mesures phénologiques décrit les réponses des plantes des régions les plus froides de notre planète aux changements expérimentaux et ambiants de température au cours des dernières décennies. La base de données contient 150434 observations phénologiques de 278 espèces de plantes prises dans 28 zones d'étude sur des périodes allant de 1 à 26 ans. Les auteurs décrivent ici l'ensemble des données afin d'accroître la

E.R. Frei. WSL Institute for Snow and Avalanche Research SLF, Fluelastrasse 11, 7260 Davos Dorf, Switzerland; Department of Geography, University of British Columbia, Vancouver, BC V6T 1Z4, Canada; Swiss Federal Institute for Forest, Snow and Landscape Research WSL, Zuercherstrasse 111, 8903 Birmensdorf, Switzerland.

G.R.H. Henry* and Z. Panchen.* Department of Geography, University of British Columbia, Vancouver, BC V6T 1Z4, Canada.

R.D. Hollister.* Biology Department, Grand Valley State University, Allendale, MI 49401-9403, USA.

T.T. Høye. Department of Bioscience and Arctic Research Centre, Aarhus University, Grenåvej 14, 8410 Rønde, Denmark. I.S. Jónsdóttir.* Life- and Environmental Sciences, University of Iceland, Sturlugata 7, 101 Reykjavík, Iceland.

J.T. Kerby. Aarhus Institute of Advanced Studies, Aarhus University, Høegh-Guldbergs Gade 6B, 8000 Aarhus, Denmark.

K. Klanderud* and $\emptyset$. Totland. Faculty of Environmental Sciences and Natural Resource Management, Norwegian University of Life Sciences, P.O. Box 5003, NO-1432 Aas, Norway.

C. Kopp. University of British Columbia, Vancouver, BC V6T 1Z4, Canada.

E. Levesque. Département des Sciences de l'environnement et Centre d'études nordiques, Université du Québec à TroisRivières, Trois-Rivières, QC G8Z 4M3, Canada.

M. Mauritz. Biological Sciences, University of Texas at El Paso, 500 West University, El Paso, TX 79902, USA.

U. Molau. Department of Biology and Environmental Sciences, University of Gothenburg, SE-405 30 Gothenburg, Sweden. I.H. Myers-Smith. University of Edinburgh, Edinburgh EH8 9YL, Scotland.

S.M. Natali. Woodwell Climate Research Center, 149 Woods Hole Road, Falmouth, MA 02540, USA

S.F. Oberbauer. Department of Biological Sciences and Institute of Environment, Florida International University, Miami, FL 33199, USA.

E. Post. Department of Wildlife, Fish, \& Conservation Biology, University of California, Davis, CA 95616, USA

C. Rixen.* WSL Institute for Snow and Avalanche Research SLF, Fluelastrasse 11, 7260 Davos Dorf, Switzerland.

H. Rodenhizer and T. Schuur. Center for Ecosystem Science and Society, Northern Arizona University, Flagstaff, AZ 86011, USA.

S.B. Rumpf. Department of Ecology \& Evolution, Bâtiment Biophore, Quartier UNIL-Sorge, University of Lausanne, 1015 Lausanne, Switzerland.

N.M. Schmidt. Aarhus University, DK-4000 Roskilde, Denmark.

P. Semenchuk. Department of Arctic and Marine Biology, Faculty of Biosciences, Fisheries and Economics, UiT-The Arctic University of Norway, N-9037 Troms $ø$, Norway; Department of Botany and Biodiversity Research, University of Vienna, Rennweg 14, 1030 Vienna, Austria.

T. Troxler. Department of Earth and Environment, Florida International University, Miami, FL 33199, USA.

H. Wahren. Research Centre for Applied Alpine Ecology, La Trobe University, Melbourne, Victoria 3086, Australia.

J.M. Welker. University of Alaska, Anchorage, AK 99508, USA; UArctic and University of Oulu, 90014 Oulu, Finland.

S. Wipf. WSL Institute for Snow and Avalanche Research SLF, Fluelastrasse 11, 7260 Davos Dorf, Switzerland; Swiss National Park, Chasté Planta-Wildenberg, 7530 Zernez, Switzerland.

Y. Yang. Swiss Federal Institute for Forest, Snow and Landscape Research WSL, Zuercherstrasse 111, 8903 Birmensdorf, Switzerland; Key Laboratory of Geographical Processes and Ecological Security in Changbai Mountains, Ministry of Education, School of Geographical Sciences, Northeast Normal University, Changchun 130024, China. 
visibilité et l'utilisation de ces données dans les analyses globales, et d'inviter les contributions de données phénologiques provenant d'endroits sous-représentés de la toundra. Des parties de cette base de données phénologiques sur la toundra ont été utilisées dans trois synthèses récentes, certains ensembles de données ont été élargis, d'autres proviennent de zones d'étude entièrement nouvelles, et l'intégralité de ces données est désormais disponible sur le Catalogue de données polaires (https://doi.org/10.21963/13215). [Traduit par la Rédaction]

Mots-clés : Arctique, alpin, changement climatique, réchauffement expérimental, International Tundra Experiment (ITEX), floraison, plante, changement de végétation.

\section{Introduction}

Changes in phenology are some of the most well-recorded and easily observable biotic responses to climate change (Parmesan and Yohe 2003; Thackeray et al. 2016; Menzel et al. 2020), and phenology observations provide important information for predicting ecosystem response to future climatic change (Diez et al. 2012). While climate change has significantly altered the phenology of many organisms around the world, the magnitude of phenological responses can differ greatly among genotypes, species, sites, ecosystems, and biomes (Primack 1980; Parmesan 2007; Post et al. 2018; Prevéy et al. 2018). The many consequences of shifts in the timing of plant flowering and growth include altered trophic interactions (Post and Forchhammer 2008; Høye et al. 2013) and changes in carbon sequestration and trace gas feedbacks (Pattison et al. 2015; Leffler et al. 2016).

The International Tundra Experiment (ITEX) was established in 1990 to examine effects of experimental warming in tundra ecosystems, using common experimental warming protocols and standardized measurements of treatment responses at plant, community, and ecosystem scales (Webber and Walker 1991; Henry and Molau 1997). Some of the first and most frequent measurements taken at ITEX sites were plant phenology observations, and the value of these coordinated observations - taken using a common protocol across sites in similar experimental conditions-has continued to grow over time (Arft et al. 1999; Prevéy et al. 2019). Phenology data from ITEX experiments have supported numerous publications, including: single-site studies (Molau et al. 2005; Bjorkman et al. 2015; Hollister et al. 2015; Panchen and Gorelick 2015; Semenchuk et al. 2016), comparisons of single taxa across sites (Alatalo and Totland 1997; Jones et al. 1997; Lévesque et al.1997; Stenström et al. 1997; Welker et al. 1997), and analyses of phenology data from multiple species and sites (Arft et al. 1999; Oberbauer et al. 2013; Prevéy et al. 2017, 2019; Assmann et al. 2019). Observations from this data set revealed that phenology of plants at colder Arctic sites is more sensitive to changes in temperature than phenology of plants from warmer Arctic sites (Arft et al. 1999; Prevéy et al. 2017); that late-flowering species flower earlier with warmer temperatures than early-flowering species-potentially leading to shorter flowering seasons with predicted warmer summers in the future (Høye et al. 2013; Prevéy et al. 2019); and that snowmelt and temperature are important drivers of plant phenology along coastal tundra sites (Assmann et al. 2019).

Although the ITEX phenology data have been used in several syntheses within the tundra biome, data from tundra sites are underrepresented in regional and global plant phenology syntheses (Parmesan and Yohe 2003; Menzel et al. 2006; Cleland et al. 2007; Cook et al. 2012; Wolkovich et al. 2012). Thus, one goal of publishing this database is to increase the visibility and accessibility of these data for use in global analyses. In addition, the phenology data set described here is the most comprehensive collection of tundra phenology observations to date, containing over 100000 more phenology observations than previously published data sets, with more phenophases, sites, and years of data than previous data sets. In 
Fig. 1. General locations of tundra study areas with plant phenology observations in the database. The size of the symbols indicates the number of years of data from study areas with either only control plots (blue circles) or both control and experimentally warmed plots (red circles). The map was created with the "ggplot2" package (Wickham 2016 ) in the statistical program $R$ ( $R$ Core Team 2020) using a base map from Natural Earth, and location data from the tundra phenology database (https://doi.org/10.21963/13215).

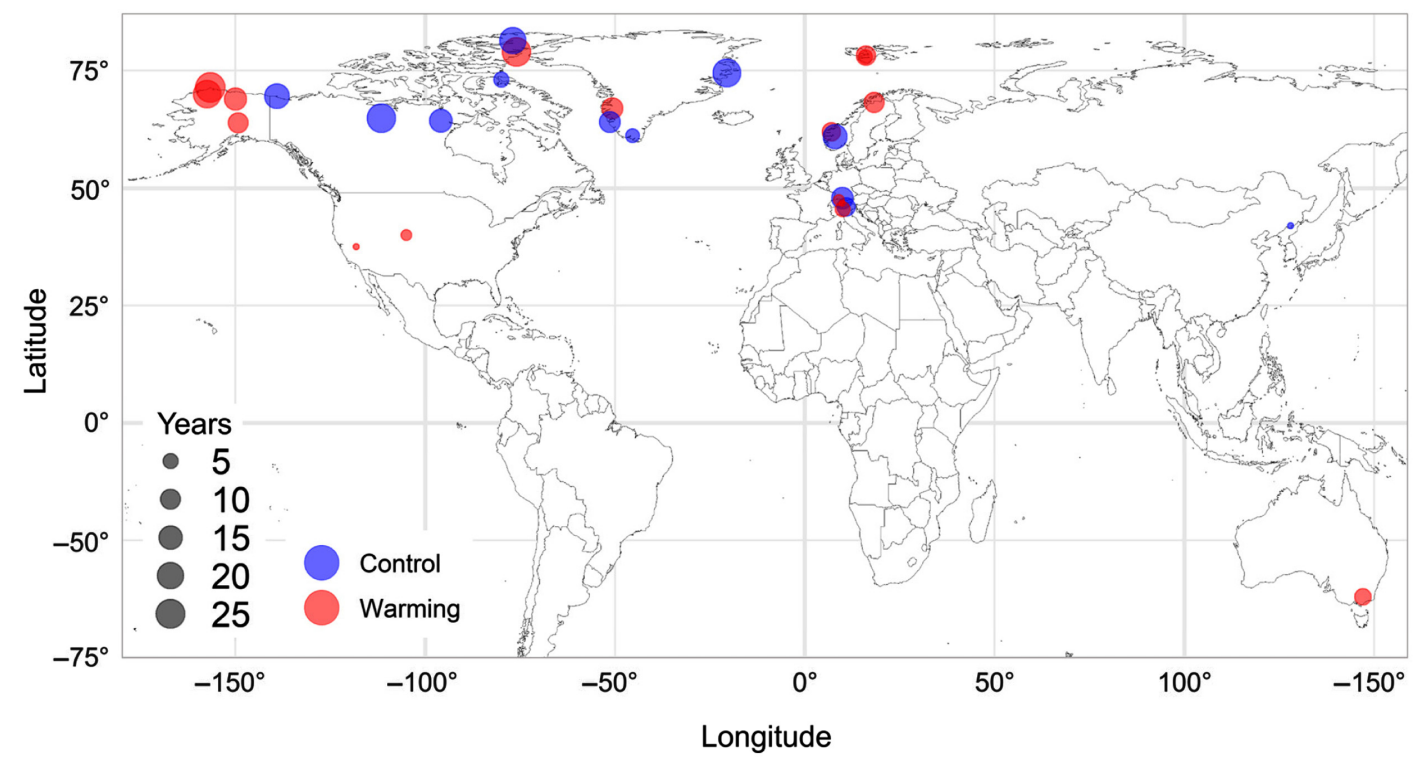

this data paper, we describe the structure and content of the tundra phenology database and establish a publicly available DOI with the Polar Data Catalogue (https://doi.org/10.21963/ 13215) where updates to the database can be added to aid in future syntheses.

\section{Materials and methods}

Study area information and experimental setup

The tundra phenology database currently contains observations from 28 study areas in tundra ecosystems (i.e., ecosystems above latitudinal or elevational tree lines, Fig. 1, Table 1, and Supplementary Table $S 1^{2}$ ). "Study areas" indicate general regions ranging in size from several hundred square meters to up to tens of kilometers. "Subsites" are smaller regions within larger study areas, either located in different habitat types or created as blocks of plots within study areas, and "plots" are the smallest study area units, located within subsites and study areas, and range in size based on the plant species of interest and landscape characteristics (Supplementary Table $\mathrm{S1}^{2}$ ). Study areas with warming experiments have clear plastic or fiberglass open-top chambers (OTCs) that were designed to artificially increase air temperature within the chambers by an average of $0.5-3{ }^{\circ} \mathrm{C}$ (Webber and Walker 1991; Marion et al. 1997; Arft et al. 1999; Bokhorst et al. 2013; Prevéy et al. 2019, Supplementary Table $S 1^{2}$ ). Variation in the amount of warming experienced in OTCs likely results from variation in habitat types and ambient climate conditions, building materials used, and differences in the height and diameter of OTCs at different study areas. The OTCs were constructed from clear fiberglass or polycarbonate materials and have

${ }^{2}$ Supplementary material is available with the article through the journal Web site at http://nrcresearchpress.com/doi/ suppl/10.1139/as-2020-0041. 
Table 1. Tundra study areas with phenology observation included in the database.

\begin{tabular}{|c|c|c|c|c|c|c|c|}
\hline Study area & Latitude & Longitude & Elevation $(\mathrm{m})$ & No. of species* & Phenophase $^{\dagger}$ & Years $^{\ddagger}$ & Treatment $^{\S}$ \\
\hline Adventdalen, Svalbard, Norway & 78.16 & 16.10 & 50 & 16 & $\begin{array}{l}\text { Flower, flowerend, green, } \\
\text { seedmat, senesce }\end{array}$ & $2007-2013$ & CTL \\
\hline \multirow[t]{5}{*}{$\begin{array}{l}\text { Alexandra Fiord, Nunavut, } \\
\text { Canada }\end{array}$} & 79.00 & -76.00 & 30 & 6 & $\begin{array}{l}\text { Flower, flowerend, green, } \\
\text { seedmat, senesce }\end{array}$ & $\begin{array}{l}2015 \\
1992-1998\end{array}$ & $\begin{array}{l}\text { CTL/OTC } \\
\text { CTL/OTC }\end{array}$ \\
\hline & & & & & & 2000-2005 & CTL/OTC \\
\hline & & & & & & $2007-2008$ & CTL/OTC \\
\hline & & & & & & 2010-2013 & CTL/OTC \\
\hline & & & & & & 2015 & CTL/OTC \\
\hline \multirow[t]{3}{*}{ Atqasuk, Alaska, USA } & 70.45 & -157.40 & 20 & 31 & $\begin{array}{l}\text { Flower, flowerend, green, } \\
\text { seedmat, senesce }\end{array}$ & 1998-2001 & CTL/OTC \\
\hline & & & & & & $2007-2008$ & CTL/OTC \\
\hline & & & & & & 2010-2019 & CTL/OTC \\
\hline Baker Lake, Nunavut, Canada & 64.38 & -95.88 & 68 & 1 & Flower, flowerend & 1992-2005 & CTL \\
\hline Bogong, Australia & -37.00 & 147.00 & 1700 & 15 & Flower, flowerend, seedmat & 2004-2009 & CTL/OTC \\
\hline Bylot Island, Nunavut, Canada & 73.13 & -80.00 & 64 & 1 & Flower, flowerend & 2001-2005 & CTL \\
\hline Changbai Mountains, China & 41.99 & 128.01 & 2123 & 4 & Flower, flowerend, green, senesce & 2018 & CTL \\
\hline $\begin{array}{l}\text { Daring Lake, Northwest } \\
\text { Territories, Canada }\end{array}$ & 64.87 & -111.53 & 420 & 8 & $\begin{array}{l}\text { Flower, flowerend, green, } \\
\text { seedmat, senesce }\end{array}$ & 1996-2019 & CTL \\
\hline Endalen, Svalbard, Norway & 78.18 & 15.76 & 94 & 6 & $\begin{array}{l}\text { Flower, flowerend, green, } \\
\text { seedmat, senesce }\end{array}$ & 2002-2005 & CTL/OTC \\
\hline \multirow[t]{2}{*}{ Faroe Islands } & 62.00 & 7.00 & 600 & 1 & Flower, flowerend & 2002 & CTL/OTC \\
\hline & & & & & & $2007-2009$ & CTL/OTC \\
\hline Finse, Norway & 60.62 & 7.52 & 1475 & 4 & Flower, flowerend, green & $\begin{array}{l}1994-1996 \\
2009\end{array}$ & $\begin{array}{l}\text { CTL/OTC } \\
\text { CTL }\end{array}$ \\
\hline Foscagno Pass, Italy & 46.47 & 10.27 & 2485 & 36 & Flower & $2007-2014$ & CTL \\
\hline Gavia Pass, Italy & 46.34 & 10.5 & 2692 & 3 & Flower, flowerend, seedmat & 2010-2014 & CTL/OTC \\
\hline Healy, Alaska, USA & 63.88 & -149.25 & 670 & 6 & Flower, green, senesce & 2010-2019 & CTL/OTC \\
\hline Jakobshorn, Switzerland & 46.77 & 9.86 & 2320 & 24 & $\begin{array}{l}\text { Flower, flowerend, green, } \\
\text { seedmat, senesce }\end{array}$ & 2015 & CTL/OTC \\
\hline Kangerlussuaq, Greenland & 67.02 & -50.72 & 200 & 14 & Flower, green, seedmat & $\begin{array}{l}2003-2004 \\
2005-2013\end{array}$ & $\begin{array}{l}\text { CTL/OTC } \\
\text { CTL }\end{array}$ \\
\hline \multirow[t]{2}{*}{ Latnjajaure, Sweden } & 68.36 & 18.49 & 1000 & 144 & $\begin{array}{l}\text { Flower, flowerend, green, } \\
\text { seedmat, senesce }\end{array}$ & 1993-1997 & CTL/OTC \\
\hline & & & & & & 1992-2001 & CTL \\
\hline Narsarsuaq, Greenland & 61.16 & -45.40 & 50,450 & 12 & Flower & 2015-2018 & CTL \\
\hline Niwot Ridge, Alaska, USA & 40.00 & -105.38 & 3528 & 12 & Flower & 2007-2008 & CTL/OTC \\
\hline Nuuk, Greenland & 64.12 & -51.35 & 5 & 3 & Flower, flowerend & 2008-2018 & CTL \\
\hline Qikiqtaruk, Nunavut, Canada & 69.58 & -139.08 & 42 & 3 & $\begin{array}{l}\text { Flower, flowerend, green, } \\
\text { seedmat, senesce }\end{array}$ & $2001-2017$ & CTL \\
\hline
\end{tabular}


Table 1. (concluded)

\begin{tabular}{|c|c|c|c|c|c|c|c|}
\hline Study area & Latitude & Longitude & Elevation (m) & No. of species* & Phenophase $^{\dagger}$ & Years $^{\ddagger}$ & Treatment $^{\S}$ \\
\hline Stillberg, Switzerland & 46.78 & 9.86 & 2180 & 7 & Flower, flowerend, green, senesce & $\begin{array}{l}2004-2005 \\
2015\end{array}$ & $\begin{array}{l}\text { CTL } \\
\text { CTL }\end{array}$ \\
\hline Tanquary Fiord, Nunavut, Canada & 81.40 & -76.87 & 4 & 2 & Flower & 1995-2014 & CTL \\
\hline Toolik Lake, Alaska, USA & 69.00 & -150.00 & 720 & 16 & $\begin{array}{l}\text { Flower, flowerend, green, } \\
\text { seedmat, senesce }\end{array}$ & 1996-2001 & CTL/OTC \\
\hline Utqiagivik, Alaska, USA & 71.31 & -156.59 & 4 & 48 & $\begin{array}{l}\text { Flower, flowerend, green, } \\
\text { seedmat, senesce }\end{array}$ & $\begin{array}{l}2007-2008 \\
1994-2001\end{array}$ & $\begin{array}{l}\text { CTL/OTC } \\
\text { CTL/OTC }\end{array}$ \\
\hline & & & & & & $\begin{array}{l}2007-2008 \\
2010-2019\end{array}$ & $\begin{array}{l}\text { CTL/OTC } \\
\text { CTL/OTC }\end{array}$ \\
\hline Val Bercla, Switzerland & 46.47 & 9.58 & 2490 & 13 & Flower, flowerend, green & $2014-2015$ & CTL/OTC \\
\hline White Mountains, Alaska, USA & 37.50 & -118.17 & 3500 & 1 & Flower, flowerend & 2013 & CTL/OTC \\
\hline Zackenberg, Greenland & 74.50 & -20.50 & 30 & 6 & Flower, flowerend & 1995-2018 & CTL \\
\hline
\end{tabular}

${ }^{*}$ No. of species is the total number of species with phenological observations at each study area.

${ }^{\dagger}$ Phenophase represents flower for first flowering dates, flowerend for last flowering dates, green for dates of first green-up of leaves, seedmat for dates of seed maturation or seed release, and senesce for dates of first observed leaf coloring in fall or leaf senescence.

†Years lists the years of data present for each data type.

${ }^{\S}$ Treatment is either CTL for control plots only or CTL/OTC for data from control and warming (open-top chamber) plots. 
a footprint of ca. 1-2 $\mathrm{m}^{2}$ (Marion et al. 1997). The OTCs were placed on plots either during the summer and removed in the winter or left on plots throughout the year, depending on the study area (Prevéy et al. 2019; Supplementary Table $S 1^{2}$ ). All warmed plots had associated control plots and some study areas continued monitoring the control plots beyond the time period during which warming treatments were applied. More details on study area and experimental characteristics for many of the study areas can be found at the ITEX Wikipedia page: https://en.wikipedia.org/wiki/International_Tundra_Experiment.

Eleven of the 28 study areas in the database were originally established as part of the ITEX network (Webber and Walker 1991; Henry and Molau 1997). Oberbauer et al. (2013) added one additional study area and years of data from 1992 through 2009 for use in a phenology synthesis paper. Most recently, phenology data from 11 additional study areas and years through 2015 were collected for three cross-site syntheses (Prevéy et al. 2017, 2019; Assmann et al. 2019). The updated phenology data set described here includes five additional study areas and years of data through 2019. A current synthesis (Collins et al. 2021) is using some of these data to examine the variation in plant responses to warming across multiple phenophases over time and with inter-annual climate.

\section{Phenology data collection protocols}

Phenology measurements collected at all original ITEX study areas were taken using a common protocol outlined in the ITEX manual (Molau and Mølgaard 1996). The standardized protocol involves checking the phenological status of plant species within study areas or plots one to three times per week over the snow-free season. Scientific names for plant species were standardized across all study areas using The Plant List (2013, v 1.1) via the package Taxonstand in the statistical program $\mathrm{R}$ ( $\mathrm{R}$ Core Team 2020). The date that a phenological event, or phenophase, is observed is recorded as the day of year and retained in this database. The five phenophases that were recorded most frequently across study areas, and are included in the database, are: green-up of leaves (green), first flowering date (flower), last flowering date (flowerend), seed maturation (seedmat), and leaf senescence (senesce; Arft et al. 1999). Phenophases were defined differently depending on plant species (Molau and Mølgaard 1996), but they were recorded consistently over time for each species at each study area (Supplementary Table S2 ${ }^{2}$ ).

For 21 of the study areas in the tundra phenology database, the phenophase observations reflect the first observed phenological event per species, plot, study area, and year (Supplementary Table S2 ${ }^{2}$ ). At these sites, flower was defined as the date when either the first flower was open, the first pollen was visible, or the first anthers were exposed, and flowerend was defined as the date when the first anthers withered or first petals dropped. Seven study areas recorded phenological events differently as noted below. At the Lapland subsite at Latnjajaure, Sweden, there were no distinct plots, so observations for this subsite reflect the first observed phenological events per species. At Baker Lake and Tanquary Fiord, Nunanvut, Canada, the phenological observations reflect the mean date of phenophases across 20-30 monitored plants at each site. The phenological observations for Narsarsuaq, Zackenberg, and Nuuk, Greenland, per plot and year reflect the dates of $50 \%$ flowering or senescence rather than the first observed open or senesced flower (Høye et al. 2013). In all cases, the manner of data collection and aggregation is consistent over time within each study area and noted in Supplementary Table $\mathrm{S2}^{2}$.

All phenology observations at all study areas were graphed and visually inspected to ensure that dates were within logical ranges, for example, phenophase observations from November through March in the Northern Hemisphere were double-checked with data owners as these would have occurred outside the short growing season in tundra ecosystems. Additionally, any phenological observation outliers that were greater than three 
standard deviations away from the mean day of year per site, species, and phenophase were double-checked with data contributors and removed if there were determined to be errors. However, we cannot ensure that the database is entirely free of errors (e.g., observations being improperly recorded on datasheets, etc.), and we reserve the right to make corrections to the database as necessary.

\section{Dataset availability and usage guidelines}

The tundra phenology database is available at the Polar Data Catalogue (www.polardata.ca): https://doi.org/10.21963/13215. Since the phenology data collection at some study areas is ongoing, and we encourage the inclusion of data from new tundra study areas, the phenology database will occasionally be updated with new years of data, or more details on study area characteristics, and each update will be released with a new version number and made available at the DOI above. We are enthusiastic to welcome new phenology observations to the database, especially from underrepresented tundra regions (Fig. 1). Principal investigators wishing to join the ITEX experimental network and contribute to the tundra phenology database should contact the corresponding author of this data paper, or visit the ITEX webpage: https://www.gvsu.edu/itex/ for more information.

The data set is fully available to the public and should be appropriately referenced by citing this data paper if used in published analyses. A large amount of time, effort, and funding has gone into conducting these frequent phenology observations in remote tundra locations. Thus, collaborating with the relevant data contributors helps recognize the huge effort of the study area principal investigators and data collectors and facilitates sitespecific interpretations of cross-site data analyses. Full recognition for data use allows investigators to secure funding for the continued collection of data at remote tundra study areas. We therefore kindly request that data users contact and invite the data contributors of relevant observations in the database as coauthors should the data set form a key contribution to the scientific analysis conducted in any resulting publications. The names and emails of data contributors are provided in the "data_provider" column of the data set.

\section{Results and data set description}

Phenology observations were collected from a total of 28 study areas in Arctic and alpine tundra ecosystems on a total of 278 plant species (Fig. 1, Table 1). Seventeen study areas include observations from both control and experimentally warmed plots, and 11 study areas include observations from only control plots (Fig. 1). There was a median of 10 and a mean of 11 years of data collected per study area, on a mean of 15 species per study area (Table 1). The earliest observations were taken in 1992 at Alexandra Fiord and Baker Lake in Nunavut, Canada, and Latnjajaure in Sweden. The most recent observations were taken in 2019 at three study areas in Alaska, USA (Utqiagvik, Atqasuk, and Healy), and Daring Lake in Northwest Territories, Canada (Table 1). The largest total number of phenology observations came from Utqiagivik, Alaska, with 60434 observations of phenological events of 48 species over 26 years in control and experimentally warmed plots. The greatest number of species observed at one study area came from Latnjajaure, Sweden, with first flowering dates of 144 species monitored over 10 years. The longest time series of observations came from Utqiagvik, Alaska, which started monitoring in 1994 and continued through 2019 in this data set, and they continue to be collected every year. The second longest period of records are the flowering phenology monitoring measurements at Zackenberg, Greenland, which started in 1996 and continued through 2018 in this release of the dataset and that also continue to be collected every year. Across all study areas over time, the numbers of observations increased from the early 1990s until 2001, and then fewer numbers of observations were recorded in the years from 2001 to 2006 (Fig. 2). This 
Fig. 2. The total number of phenology observations of each phenophase type across all study areas in the database per year. Flower observations are first flowering dates. Flowerend observations are last flowering dates. Green observations are leaf green-up dates. SeedMat observations are seed maturation or seed dispersal dates. Senesce observations are leaf senescence dates.

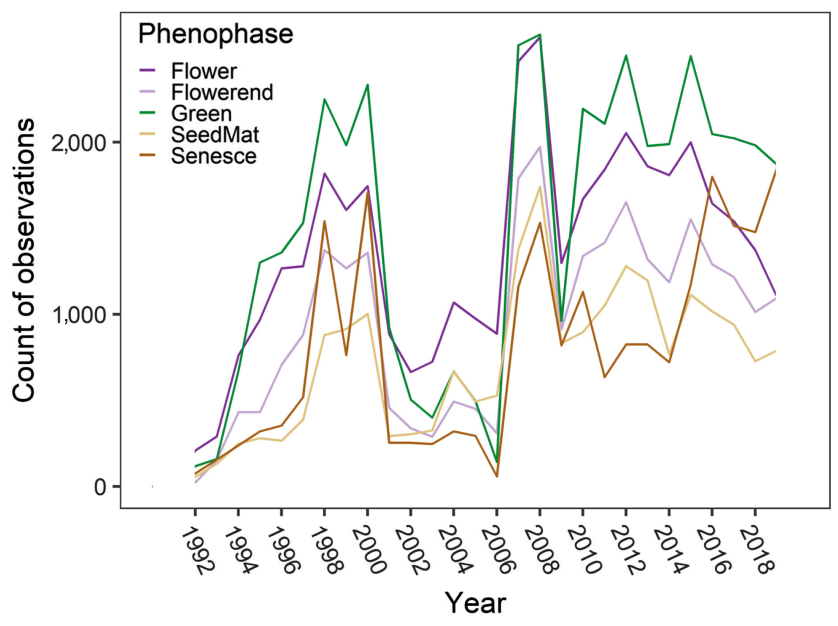

Fig. 3. The total number of observations of each phenophase taken at (A) the 23 study areas with $<6000$ observations each and (B) the study areas with $>6000$ observations each. Note the change in scale between (A) and (B) on the $y$ axes. Flower observations are first flowering dates. Flowerend observations are last flowering dates. Green observations are leaf green-up dates. SeedMat observations are seed maturation or seed dispersal dates. Senesce observations are leaf senescence dates.
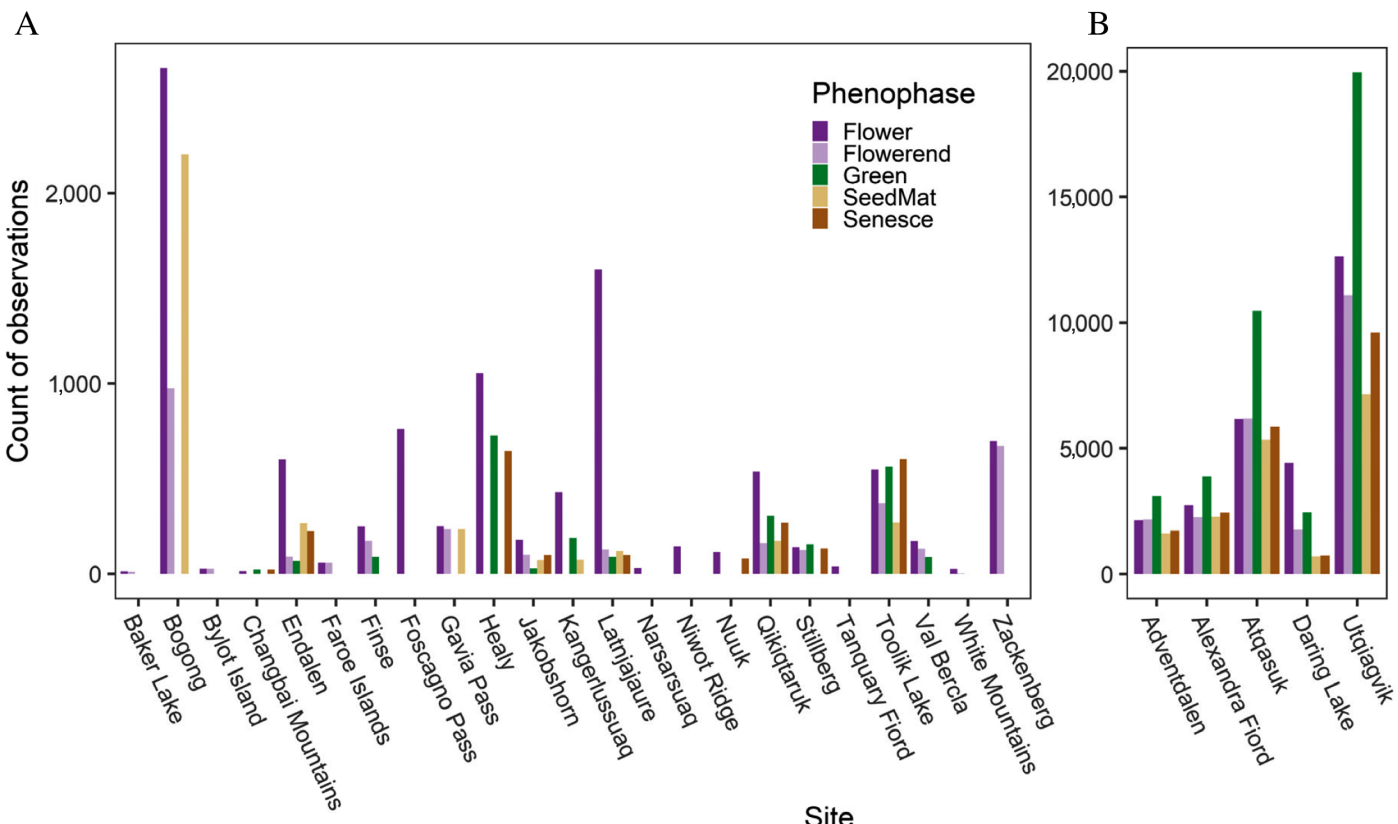

- Published by Canadian Science Publishing 
Fig. 4. (A) The day of year (DOY) of flowering observations by year across all Arctic and alpine tundra study areas that recorded flowering, colored by study area latitude. The DOYs for the southern hemisphere were shifted by 6 months to match those from the northern hemisphere sites. (B) The number of flowering observations recorded by latitude colored by study area latitude. (C) Locations of study areas with flowering observations, colored by study area latitude. The map was created with the ggplot2 package (Wickham 2016) in the statistical program R (R Core Team 2020) using a base map from Natural Earth, and location data from the tundra phenology database (https://doi.org/10.21963/13215).

A

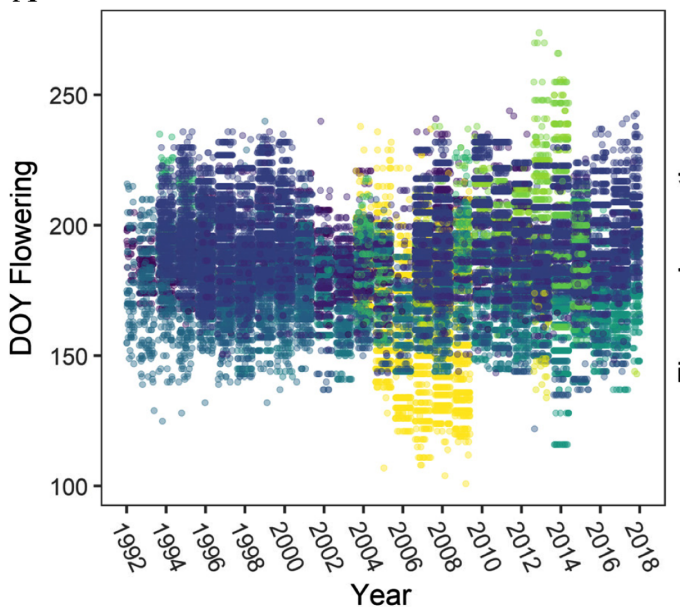

B

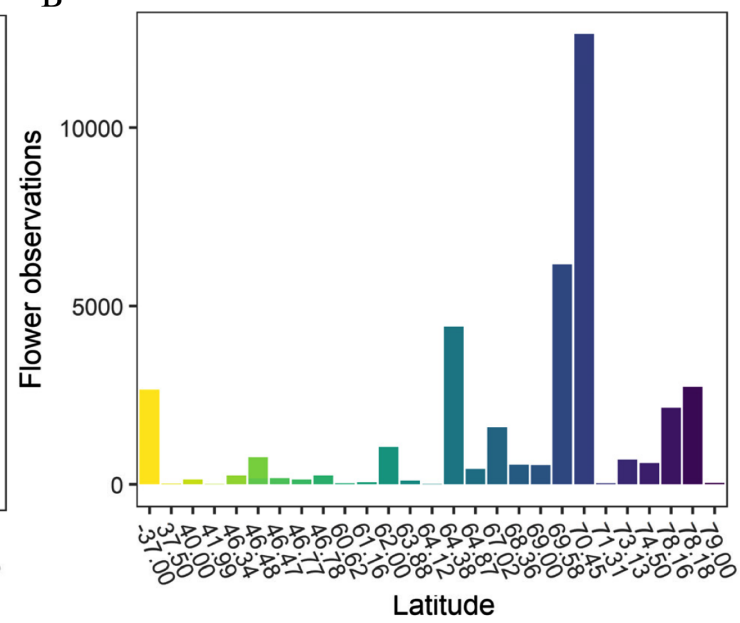

$\mathrm{C}$

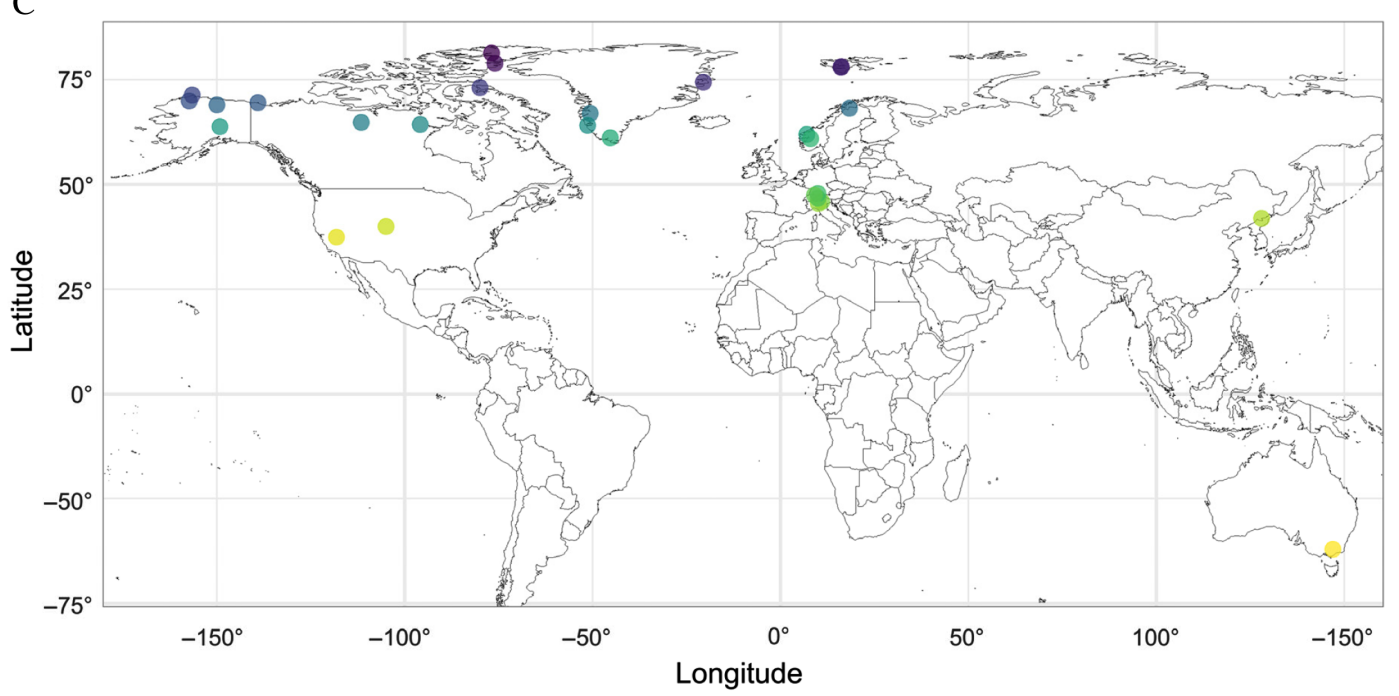

was followed by a large increase in the number of observations the following two years, with the most observations taken in 2008 , likely boosted by an increase in funding for field observations from the fourth International Polar Year in 2007 and 2008 (Fig. 2).

At the time of publication, the database contains 42203 observations of green-up (green), 38443 observations of first flowering dates (flower), 26723 observations of last flowering dates (flowerend), 22559 observations of leaf senescence (senesce), and 20506 observations of seed maturation (seedmat; Fig. 3). Phenological events that happen earlier in the summer (green-up, first flowering dates) are almost twice as numerous in the data set than late-season events (leaf senescence, seed maturation), possibly because of 
Table 2. Structure of the tundra phenology database.

\begin{tabular}{|c|c|}
\hline Column heading & Description \\
\hline study_area & Study area name \\
\hline subsite & Name of subsite location within study area (if applicable) \\
\hline soil_moisture & $\begin{array}{l}\text { General classification of the soil moisture status at a study area or subsite: dry } \\
\text { (containing roughly <20\% gravimetric soil moisture content (GMC)), moist }(20 \%-60 \% \\
\text { GMC), or wet }(>60 \% \text { GMC) }\end{array}$ \\
\hline lat & Latitude, decimal degrees $\mathrm{N}$ \\
\hline long & Longitude, decimal degrees $\mathrm{E}$ \\
\hline elevation & Elevation (above sea level) in meters \\
\hline ecosystem & $\begin{array}{l}\text { Tundra ecosystem type: Arctic (north of latitudinal treeline) or alpine (above elevational } \\
\text { treeline) }\end{array}$ \\
\hline exstart & Year the experiment or monitoring began at each study area \\
\hline year & Year of the phenological observation \\
\hline treatment & $\begin{array}{l}\text { Experimental treatment, either CTL (control) or OTC (open-top chamber - } \\
\text { experimentally warmed) }\end{array}$ \\
\hline plot & Plot within study area or subsite (if applicable) \\
\hline spp & Species abbreviation \\
\hline woody & Indicating whether a species is woody (woody) or not (herb) \\
\hline functional group & Forb, graminoid, evergreen shrub or deciduous shrub \\
\hline genus & Scientific name of plant genus \\
\hline species & Scientific name of plant species \\
\hline phenophase & The phenological event observed (flower, flowerend, green, seedmat, senesce) \\
\hline DOY & Day of year the phenophase was first observed (from 1 to 366 ) \\
\hline snowfree_date & First snow-free day of year per plot or study area if available (from 1 to 366 ) \\
\hline data_provider & Name of the study area principal investigator or data provider of the observation \\
\hline data_provider_email & Email of the data provider \\
\hline
\end{tabular}

Note: The database is provided as a .csv file of a single data table structured by the following column headings and descriptions. Each row in the data table corresponds to a phenological observation.

herbivory, early snowfall, or because it is difficult to staff seasonal personal through late August and September in remote tundra locations when later phenological events may be occurring.

Twenty-six percent of the observations in the database were first flowering observations, with all 28 study areas recording this event over a mean of 10.8 years (Figs. 3 and 4). There was a large range in flowering dates among species, study areas, plots, and years (Fig. 4), with an average range of 54 days among flowering dates within a year at study areas that recorded flowering of six species or more (Fig. 4). The structure of the database and variable descriptions are provided in Table 2.

\section{Conclusions}

To our knowledge, this database represents the largest collection of repeated phenology observations of plant species from across the tundra biome. This large collection of data has the potential to be used in future syntheses of vegetation response to climate change, both globally and locally. These data could be used to inform and refine climate-vegetation models and, among many other research directions, help predict phenology in tundra regions where phenological mismatch between vegetation, herbivores, and (or) pollinators could occur as the climate changes.

\section{Acknowledgements}

Pat Webber and Terry Callaghan were the initial leaders of ITEX building on their involvement in the IBP Polar Biome program, and we thank them for their vision for this network. We thank A. Maria Fosaa for establishing the ITEX site in the Faroe Islands. We thank M. Dalle Fratte, D. Cooley, O. Durey, C. Eckert, J. F. Johnstone, C. Kennedy, V. 
Lamarre, G. Levasseur, C. Spiech, J. Svoboda, and R. Wising; the Herschel Island Qikiqtaruk Territorial Park staff, including E. McLeod, S. McLeod, R. Joe, P. Lennie, D. Arey, S. Goosen, D. Gordon, L. Meyook, J. McLeod, P. Foisy, C. Gordon, J. Hansen, A. Rufus, and R. Gordon; Quttinirpaaq National Park staff; the Greenland Ecosystem Monitoring program; the Warming and species Removal in Mountains (WaRM) coordinators, N. Sanders, A. Classen, and M. Sundqvist; as well as the many other individuals who established experiments and collected detailed phenology observations. We thank local communities for welcoming our research teams on their land, the Qamani'tuaq, Mittimatalik, Aujuittuq, Iñupiat, Waveroo, Cheyenne, Resolute Bay, and Finse Alpine Research Center, among many others. These observations were made possible with the support of many funding agencies and grants, including: ArcticNet; the Natural Sciences and Engineering Research Council of Canada; the Canadian International Polar Year Program; the Polar Continental Shelf Program of Natural Resources Canada; the Northern Scientific Training Program, Polar Knowledge Canada; the W. Garfield Weston Foundation; the Danish Environmental Protection Agency; the Swiss Federal Institute for Forest, Snow and Landscape Research WSL; the National Geographic Society; the US National Science Foundation (grant numbers PLR1525636, PLR1504141, PLR1433063, PLR1107381, PLR0119279, PLR0902125, PLR0856728, PLR1312402, PLR1019324, LTER 1026415, OPP1525636, OPP9907185, DEB1637686, 0856710, 9714103, 0632263, 0856516, 1432277, 1432982, 1504381, 1504224, 1433063, 0856728, 0612534, 0119279, 9421755, 0632184, 9617643, and 9321730; the Swiss National Science Foundation (155554); the Danish National Research Foundation (grant CENPERM DNRF100); the Danish Council for Independent Research (Natural Sciences grant DFF 4181-00565); the Deutsche Forschungsgemeinschaft (grant: RU 1536/3-1); the Natural Environment Research Council (grant NE/M016323/1); European Union's Horizon 2020 research and innovation programme under the Marie Skłodowska-Curie (grant 754513), the Aarhus University Research Foundation, the Department of Energy (grant SC006982); a Semper Ardens grant from the Carlsberg Foundation to N.J. Sanders; The Strategic Research Area BECC (Biodiversity and Ecosystems in a Changing Climate) to UM and MPB; and an INTERACT Transnational Access grant to JSP. This work was supported by the Norwegian Research Council SnoEco project, grant number 230970 to E.J. Cooper, The Villum Foundation (grant 17523), the Carlsberg foundation (grant CF14-0992), and by the U.S. Department of Energy, Office of Biological and Environmental Research, Terrestrial Ecosystem Science (TES) Program Awards \#DE-SC0006982, \#DE-SC0014085, \#DE-SC0020227.

\section{References}

Alatalo, J.M., and Totland, Ø. 1997. Response to simulated climatic change in an alpine and subarctic pollen-risk strategist, Silene acaulis. Global Change Biol. 3: 74-79. doi: 10.1111/j.1365-2486.1997.gcb133.x.

Arft, A.M., Walker, M.D., Gurevitch, J., Alatalo, J.M., Bret-Harte, M.S., Dale, M., et al. 1999. Responses of tundra plants to experimental warming: meta-analysis of the International Tundra Experiment. Ecol. Monogr. 69: 491-511. doi: 10.1890/0012-9615(1999)069[0491:ROTPTE]2.0.CO;2.

Assmann, J.J., Myers-Smith, I.H., Phillimore, A.B., Bjorkman, A.D., Ennos, R.E., Prevéy, J.S., et al. 2019. Local snow melt and temperature - but not regional sea ice - explain variation in spring phenology in coastal Arctic tundra. Global Change Biol. 25: 2258-2274. doi: 10.1111/gcb.14639.

Bjorkman, A.D., Elmendorf, S.C., Beamish, A.L., Vellend, M., and Henry, G.H.R. 2015. Contrasting effects of warming and increased snowfall on Arctic tundra plant phenology over the past two decades. Global Change Biol. 21: 4651-4661. doi: 10.1111/gcb.13051.

Bokhorst, S., Huiskes, A., Aerts, R., Convey, P., Cooper, E.J., Dalen, L., et al. 2013. Variable temperature effects of Open Top Chambers at polar and alpine sites explained by irradiance and snow depth. Global Change Biol. 19: 64-74. doi: $10.1111 / g c b .12028$.

Cleland, E.E., Chuine, I., Menzel, A., Mooney, H.A., and Schwartz, M.D. 2007. Shifting plant phenology in response to global change. Trends Ecol. Evol. 22: 357-365. doi: 10.1016/j.tree.2007.04.003. PMID: 17478009. 
Collins, C.G., Elmendorf, S.C., Hollister, R.D., Henry, G.H.R., Clark, K., Bjorkman, A.D., et al. 2021. Experimental warming differentially affects vegetative and reproductive phenology of tundra plants. Nat. Commun. $12: 3442$. doi: 10.1038/s41467-021-23841-2.

Cook, B.I., Wolkovich, E.M., and Parmesan, C. 2012. Divergent responses to spring and winter warming drive community level flowering trends. Proc. Natl. Acad. Sci. USA, 109: 9000-9005. doi: 10.1073/pnas.1118364109. PMID: 22615406.

Diez, J.M., Ibáñez, I., Miller-Rushing, A.J., Mazer, S.J., Crimmins, T.M., Crimmins, M.A., et al. 2012. Forecasting phenology: from species variability to community patterns. Ecol. Lett. 15: 545-553. doi: 10.1111/j.14610248.2012.01765.x. PMID: 22433120.

Henry, G.R., and Molau, U. 1997. Tundra plants and climate change: the International Tundra Experiment (ITEX). Global Change Biol. 3(Suppl. 1): 1-9. doi: 10.1111/j.1365-2486.1997.gcb132.x.

Hollister, R.D., May, J.L., Kremers, K.S., Tweedie, C.E., Oberbauer, S.F., Liebig, J.A., et al. 2015. Warming experiments elucidate the drivers of observed directional changes in tundra vegetation. Ecol. Evol. 5: 1881-1895. doi: 10.1002/ ece3.1499. PMID: 26140204.

Høye, T.T., Post, E., Schmidt, N.M., Trøjelsgaard, K., and Forchhammer, M.C. 2013. Shorter flowering seasons and declining abundance of flower visitors in a warmer Arctic. Nat. Clim. Change, 3: 759-763. doi: 10.1038/ nclimate1909.

Jones, M.H., Bay, C., and Nordenhäll, U. 1997. Effects of experimental warming on arctic willows (Salix spp.): a comparison of responses from the Canadian High Arctic, Alaskan Arctic, and Swedish Subarctic. Global Change Biol. 3: 55-60. doi: 10.1111/j.1365-2486.1997.gcb135.x.

Leffler, A.J., Klein, E.S., Oberbauer, S.F., and Welker, J.M. 2016. Coupled long-term summer warming and deeper snow alters species composition and stimulates gross primary productivity in tussock tundra. Oecologia, 181: 287-297. doi: 10.1007/s00442-015-3543-8. PMID: 26747269.

Lévesque, E., Henry, G.H.R., and Svoboda, J. 1997. Phenological and growth responses of Papaver radicatum along altitudinal gradients in the Canadian High Arctic. Global Change Biol. 3: 125-145. doi: 10.1111/j.13652486.1997.gcb145.x.

Marion, G.M., Henry, G.H.R., Freckman, D.W., Johnstone, J., Jones, G., Jones, M.H., et al. 1997. Open-top designs for manipulating field temperature in high-latitude ecosystems. Global Change Biol. 3: 20-32. doi: 10.1111/j.13652486.1997.gcb136.x.

Menzel, A., Sparks, T.H., Estrella, N., Koch, E., Aasa, A., Ahas, R., et al. 2006. European phenological response to climate change matches the warming pattern. Global Change Biol. 12: 1969-1976. doi: 10.1111/j.13652486.2006.01193.X.

Menzel, A., Yuan, Y., Matiu, M., Sparks, T., Scheifinger, H., Gehrig, R., and Estrella, N. 2020. Climate change fingerprints in recent European plant phenology. Global Change Biol. 26: 2599-2612. doi: 10.1111/gcb.15000.

Molau, U., and Mølgaard, P. 1996. International tundra experiment (ITEX) manual. Danish Polar Center, Copenhagen, Denmark.

Molau, U., Nordenhäll, U., and Eriksen, B. 2005. Onset of flowering and climate variability in an alpine landscape: a 10-year study from Swedish Lapland. Am. J. Bot. 92: 422-431. doi: 10.3732/ajb.92.3.422. PMID: 21652418.

Oberbauer, S.F., Elmendorf, S.C., Troxler, T.G., Hollister, R.D., Rocha, A.V., Bret-Harte, M.S., et al. 2013. Phenological response of tundra plants to background climate variation tested using the International Tundra Experiment. Philos. Trans. R. Soc. Lond. B: Biol. Sci. 368: 20120481. doi: 10.1098/rstb.2012.0481. PMID: 23836787.

Panchen, Z.A., and Gorelick, R. 2015. Flowering and fruiting responses to climate change of two Arctic plant species, purple saxifrage (Saxifraga oppositifolia) and mountain avens (Dryas integrifolia). Arct. Sci. 1: 45-58. doi: 10.1139/as-2015-0016.

Parmesan, C. 2007. Influences of species, latitudes and methodologies on estimates of phenological response to global warming. Global Change Biol. 13: 1860-1872. doi: 10.1111/j.1365-2486.2007.01404.x.

Parmesan, C., and Yohe, G. 2003. A globally coherent fingerprint of climate change impacts across natural systems. Nature, 421: 37-42. doi: 10.1038/nature01286. PMID: 12511946.

Pattison, R.R., Jorgenson, J.C., Raynolds, M.K., and Welker, J.M. 2015. Trends in NDVI and tundra community composition in the Arctic of NE Alaska between 1984 and 2009. Ecosystems, 18: 707-719. doi: 10.1007/s10021-0159858-9.

Post, E., and Forchhammer, M.C. 2008. Climate change reduces reproductive success of an Arctic herbivore through trophic mismatch. Philos. Trans. R. Soc. Lond. B: Biol. Sci. 363: 2367-2373. doi: 10.1098/rstb.2007.2207.

Post, E., Steinman, B.A., and Mann, M.E. 2018. Acceleration of phenological advance and warming with latitude over the past century. Sci. Rep. 8: 3927. doi: 10.1038/s41598-018-22258-0. PMID: 29500377.

Prevéy, J., Vellend, M., Rüger, N., Hollister, R.D., Bjorkman, A.D., Myers-Smith, I.H., et al. 2017. Greater temperature sensitivity of plant phenology at colder sites: implications for convergence across northern latitudes. Global Change Biol. 23: 2660-2671. doi: 10.1111/gcb.13619.

Prevéy, J.S., Harrington, C.A., and St. Clair, J.B. 2018. The timing of flowering in Douglas-fir is determined by coolseason temperatures and genetic variation. For. Ecol. Manage. 409: 729-739. doi: 10.1016/j.foreco.2017.11.062.

Prevéy, J.S., Rixen, C., Rüger, N., Høye, T.T., Bjorkman, A.D., Myers-Smith, I.H., et al. 2019. Warming shortens flowering seasons of tundra plant communities. Nat. Ecol. Evol. 3: 45-52. doi: 10.1038/s41559-018-0745-6. PMID: 30532048.

Primack, R.B. 1980. Variation in the phenology of natural populations of Montane shrubs in New Zealand. J. Ecol. 68: 849-862. doi: $10.2307 / 2259460$. 
R Core Team. 2020. R: a language and environment for statistical computing. R Foundation for Statistical Computing, Vienna, Austria. Available from https://www.R-project.org/.

Semenchuk, P.R., Gillespie, M.A.K., Rumpf, S.B., Baggesen, N., Elberling, B., and Cooper, E.J. 2016. High Arctic plant phenology is determined by snowmelt patterns but duration of phenological periods is fixed: an example of periodicity. Environ. Res. Lett. 11: 125006. doi: 10.1088/1748-9326/11/12/125006.

Stenström, M., Gugerli, F., and Henry, G.H.R. 1997. Response of Saxifraga oppositifolia L. to simulated climate change at three contrasting latitudes. Global Change Biol. 3: 44-54. doi: 10.1111/j.1365-2486.1997.gcb144.x.

Thackeray, S.J., Henrys, P.A., Hemming, D., Bell, J.R., Botham, M.S., Burthe, S., et al. 2016. Phenological sensitivity to climate across taxa and trophic levels. Nature, 535: 241-245. doi: 10.1038/nature18608. PMID: 27362222.

Webber, P.J., and Walker, M.D. 1991. The International Tundra Experiment (ITEX): resolution. Arct. Alp. Res. $23: 124$. Welker, J.M., Molau, U., Parsons, A.N., Robinson, C.H., and Wookey, P.A. 1997. Responses of Dryas octopetala to ITEX environmental manipulations: a synthesis with circumpolar comparisons. Global Change Biol. 3: 61-73. doi: 10.1111/j.1365-2486.1997.gcb143.x.

Wickham, H. 2016. ggplot2: elegant graphics for data analysis. Springer-Verlag, New York, N.Y., USA.

Wolkovich, E.M., Cook, B.I., Allen, J.M., Crimmins, T.M., Betancourt, J.L., Travers, S.E., et al. 2012. Warming experiments underpredict plant phenological responses to climate change. Nature, 485: 494-497. doi: 10.1038/ nature11014. PMID: 22622576. 